\title{
Cerebrovascular Dysfunction in Amyloid Precursor Protein Transgenic Mice: Contribution of Soluble and Insoluble Amyloid- $\beta$ Peptide, Partial Restoration via $\gamma$-Secretase Inhibition
}

\author{
Byung Hee Han, ${ }^{1}$ Meng-liang Zhou, ${ }^{1}$ Fadi Abousaleh, ${ }^{1}$ Robert P. Brendza, ${ }^{2}$ Hans H. Dietrich, ${ }^{1}$ \\ Jessica Koenigsknecht-Talboo, ${ }^{2}$ John R. Cirrito, ${ }^{2,4}$ Eric Milner, ${ }^{1}$ David M. Holtzman, ${ }^{2,3,4}$ and Gregory J. Zipfel ${ }^{1,2,4}$ \\ Departments of ${ }^{1}$ Neurological Surgery, ${ }^{2}$ Neurology, and ${ }^{3}$ Developmental Biology, and the ${ }^{4}$ Hope Center for Neurological Disorders, Washington University \\ School of Medicine, St. Louis, Missouri 63110
}

\begin{abstract}
The contributing effect of cerebrovascular pathology in Alzheimer's disease (AD) has become increasingly appreciated. Recent evidence suggests that amyloid- $\beta$ peptide $(\mathrm{A} \beta)$, the same peptide found in neuritic plaques of $\mathrm{AD}$, may play a role via its vasoactive properties. Several studies have examined young Tg2576 mice expressing mutant amyloid precursor protein (APP) and having elevated levels of soluble $\mathrm{A} \beta$ but no cerebral amyloid angiopathy (CAA). These studies suggest but do not prove that soluble $\mathrm{A} \beta$ can significantly impair the cerebral circulation. Other studies examining older Tg2576 mice having extensive CAA found even greater cerebrovascular dysfunction, suggesting that CAA is likely to further impair vascular function. Herein, we examined vasodilatory responses in young and older Tg2576 mice to further assess the roles of soluble and insoluble $A \beta$ on vessel function. We found that (1) vascular impairment was present in both young and older Tg2576 mice; (2) a strong correlation between CAA severity and vessel reactivity exists; (3) a surprisingly small amount of CAA led to marked reduction or complete loss of vessel function; 4) CAA-induced vasomotor impairment resulted from dysfunction rather than loss or disruption of vascular smooth muscle cells; and 5) acute depletion of $A \beta$ improved vessel function in young and to a lesser degree older $\operatorname{Tg} 2576$ mice. These results strongly suggest that both soluble and insoluble $\mathrm{A} \beta$ cause cerebrovascular dysfunction, that mechanisms other than $\mathrm{A} \beta$-induced alteration in vessel integrity are responsible, and that anti- $\mathrm{A} \beta$ therapy may have beneficial vascular effects in addition to positive effects on parenchymal amyloid.
\end{abstract}

Key words: cerebral amyloid angiopathy; amyloid- $\beta$; vascular function; $\gamma$-secretase; hypercapnia; Alzheimer's disease

\section{Introduction}

There is compelling evidence that the amyloid- $\beta$ peptide $(\mathrm{A} \beta)$, a cleavage product of amyloid precursor protein (APP), is a key factor in the pathogenesis of Alzheimer's disease (AD) (Sisodia, 1999; Selkoe, 2001; Golde, 2005). Changes in A $\beta$ conformation from soluble monomeric $A \beta$ to oligomers and insoluble amyloid fibrils are likely critical events in AD pathogenesis (Golde et al., 2000). Yet converging lines of evidence suggest that other factors may also play key roles. One such factor is cerebrovascular disease (Iadecola, 2004). AD patients have increased incidence of vascular brain lesions (Snowdon et al., 1997). They also have substantial cerebrovascular dysfunction at very early stages in their dis-

\footnotetext{
Received Sept. 30, 2008; accepted 0ct. 29, 2008.

This work was supported by National Institutes of Health (NIH) Grants NS053899 (G.J.Z.) and NS032636 (D.M.H.), grants from the American Association of Neurological Surgeons/Congress of Neurological Surgeons (G.J.Z.) and American Health Assistance Foundation (G.J.Z. and R.P.B.), NIH Neuroscience Blueprint Core Grant NS057105 to Washington University, and Eli Lilly and Co. We thank Robert Mach for providing Methoxy-X04 for these studies.

Correspondence should be addressed to Dr. Gregory J. Zipfel, Department of Neurological Surgery, Campus Box 8057, Washington University School of Medicine, 660 South Euclid Avenue, St. Louis, M0 63110. E-mail: zipfelg@nsurg.wustl.edu.

DOI:10.1523/JNEUROSCI.4686-08.2008

Copyright $\odot 2008$ Society for Neuroscience $\quad$ 0270-6474/08/2813542-09\$15.00/0
}

ease (Prohovnik et al., 1988; Hock et al., 1997; Jagust et al., 1998; Mentis et al., 1998; de la Torre, 2004). Most importantly, when neurodegenerative and vascular features coexist, they appear to act synergistically to cause dementia (Snowdon et al., 1997; Lim et al., 1999; Vermeer et al., 2003).

Another link between cerebrovascular disease and AD is cerebral amyloid angiopathy (CAA). CAA is characterized by A $\beta$ deposition within walls of leptomeningeal and cortical arterioles. It is almost universally found in AD patients (Mandybur, 1975; Glenner et al., 1981; Vinters, 1987; Esiri et al., 1999; Jellinger, 2002). CAA may in fact account for at least some of the cerebrovascular observations noted above, because numerous studies document its contribution to ischemic brain injury (Okazaki et al., 1979; Greenberg et al., 1993; Premkumar et al., 1996; Breteler, 2000; Cadavid et al., 2000) as well as intracerebral hemorrhage (Itoh et al., 1993; Mann et al., 1996). These human observations are complemented by studies in $\mathrm{AD}$ mouse models demonstrating that soluble and insoluble $\mathrm{A} \beta$ can disrupt the cerebral circulation. For example, young APP mice having elevated levels of both APP and soluble $\mathrm{A} \beta$ (but no CAA) have impaired cerebral blood flow responses to vasodilatory stimuli (Zhang et al., 1997; Iadecola et al., 1999; Niwa et al., 2000a,b, 2002a; Park et al., 2004, 2005, 2008; 
Tong et al., 2005). Impaired cerebral function has also been noted in older APP mice having extensive CAA (Christie et al., 2001; Shin et al., 2007; Park et al., 2008). Because these transgenic mice overexpress APP as well as A $\beta$, it has not been conclusively proven that the observed cerebrovascular dysfunction is due to A $\beta$ vs APP.

To further assess the contribution of soluble and insoluble $\mathrm{A} \beta$ on cerebrovascular function, we examined vasomotor responses and structural integrity of individual cerebral vessels in young (6 month; pre-CAA) and older (12-15 month; extensive CAA) Tg2576 mice that overexpress mutant APP. In young Tg2576 mice, we found that responses to vasodilatory stimuli were impaired, that vascular smooth muscle cell (VSMC) dysfunction contributed to this impairment, and that $\gamma$-secretase inhibition substantially restored cerebrovascular function. In older Tg2576 mice, we noted more severe vascular impairment that also appeared mediated in part via VSMC dysfunction. We identified a significant dose-response between extent of vasodilation and CAA severity, and we found that vessel dysfunction began at a surprisingly early stage of CAA that preceded significant alterations in vessel integrity. Finally, $\gamma$-secretase inhibition in older Tg2576 mice produced a significant but less robust restoration of vasomotor function. In total, these results strongly suggest that both soluble and insoluble forms of $\mathrm{A} \beta$ cause cerebrovascular impairment, that VSMC dysfunction at least in part underlies this impairment, that mechanisms other than $\mathrm{A} \beta$-induced disruption of vessel integrity are involved, and that anti-A $\beta$ strategies have the capacity to reverse at least some forms of $\mathrm{A} \beta$-induced vessel dysfunction.

\section{Materials and Methods}

Animals and surgical procedure. All experimental protocols were approved by the animal studies committee at Washington University. The production, genotyping, and background strain (B6/SJL) of Tg2576 mice used in this study have been described previously (Hsiao et al., 1996; Holtzman et al., 2000). Tg2576 mice overexpress human APP695 with the familial Swedish AD mutations at positions 670/671 under control of the hamster prion protein $(\mathrm{PrP})$ promoter and were generous gift from Dr. K. Ashe (University of Minnesota, Minneapolis, MN). A closed cranial window preparation was performed as previously reported with modification (Christie et al., 2001; Brendza et al., 2005). Briefly, mice were anesthetized with isoflurane (4\% induction, $1.5 \%$ maintenance), and a $4 \mathrm{~mm}$ diameter craniotomy was performed with a water-cooled dental drill in the right parietal bone. The craniotomy was filled artificial CSF (aCSF [in mm: $125 \mathrm{NaCl}, 26 \mathrm{NaHCO}_{3}, 1.25 \mathrm{NaH}_{2} \mathrm{PO}_{4}, 2.5 \mathrm{KCl}, 1$ $\mathrm{MgCl}_{2}, 1 \mathrm{CaCl}_{2}$, and 25 glucose]) and sealed to the bone with a microscope coverglass using dental cement. In select experiments, two SILASTIC tubings (inner diameter: $0.3 \mathrm{~mm}$, outer diameter: $0.64 \mathrm{~mm}$; Dow Corning) were inserted through the bone wax to permit topical application of vasodilators. Mice were returned to their cages for the recovery with access to food and water ad libitum.

Cerebral vasodilatory responses. Fifteen hours later, mice were anesthetized with isoflorane and $\alpha$-chloralose ( $80 \mathrm{mg} / \mathrm{kg}$, i.p.) and ventilated at a stroke volume of $5 \mathrm{ml} / \mathrm{kg}$ body weight and ventilation rate of 150 strokes/ min with a rodent ventilator (Harvard Apparatus). Core body temperature was maintained at $37^{\circ} \mathrm{C}$ by a thermo-regulated heating pad (Cell MicroControls). An arterial catheter was placed into the femoral artery for measuring mean arterial blood pressure and blood gases. The mouse was then placed in a custom-built stereotaxic device to secure its head on the microscope stage. The leptomeningeal vessels were visualized using a Nikon Eclipse 600ME digital video microscopy system and MetaMorph imaging software (Molecular Devices). Vessel diameter response to hypercapnia or topical vasodilators was then assessed. To induce hypercapnia, mice were ventilated with $5 \% \mathrm{CO}_{2} / 30 \% \mathrm{O}_{2}$-containing air for $5 \mathrm{~min}$ followed by ventilation with $30 \% \mathrm{O}_{2}$-containing air. Blood gases were analyzed before, $4 \mathrm{~min}$ after hypercapnia, and $4 \mathrm{~min}$ after recovery. For vasodilator experiments, the endothelium-dependent vasodilator acetylcholine (ACh; $100 \mu \mathrm{M}$; Sigma) or the VSMC-dependent vasodilator $S$-nitroso- $N$-acetyl-penicillamine (SNAP; $500 \mu \mathrm{M}$; Sigma) was infused into the cranial window at a rate of $20 \mu \mathrm{l} / \mathrm{min}$ for $5 \mathrm{~min}$. The cranial window was then infused with aCSF for 20-30 min or until the vessel diameter returned to its baseline value. The order of vasodilatory agents was randomly assigned. To examine the effect of $\gamma$-secretase inhibition on vasodilatory responses, mice received subcutaneously the potent, blood-brain barrier permeable $\gamma$-secretase inhibitor, LY411,575 or its inactive enantiomer, LY424,196 (generous gift from Pat May, Eli Lilly and Co) $15 \mathrm{~h}$ before vascular imaging.

Vessel diameter measurement. Vessel diameters were determined with Diamtrak software (Tim Neild, Monash University, Melbourne, Australia). Averaged vessel diameter across a $25 \mu \mathrm{m}$ longitudinal segment (8 consecutive segments per mouse) of the dorsal middle cerebral arteries were analyzed before (baseline) and 3-5 min after treatment with vasodilatory stimuli (see Fig. 2 A). Data were calculated as $\%$ vasodilation vs baseline vessel diameter

CAA quantification. To label amyloid deposits in the brain, mice were i.p. injected with a Congo red derivative, Methoxy-X04 (10 mg/kg) $15 \mathrm{~h}$ before vascular imaging as described previously (Klunk et al., 2002; Brendza et al., 2005). Utilizing the threshold function in MetaMorph software, \% CAA coverage in each $25 \mu \mathrm{m}$-long segment of the pial vessels (8 segments per brain) was determined.

VSMC staining and two-photon microscopy. After live brain imaging described above, mice were perfused with PBS. Brains were removed, fixed in $4 \%$ paraformaldehyde, and preserved in 30\% glucose-PBS solution at $4^{\circ} \mathrm{C}$. To label VSMCs, fixed whole brains were permeabilized with PBS containing $0.25 \%$ Triton X-100 for $20 \mathrm{~min}$ at room temperature, blocked with $2 \%$ bovine serum albumin (BSA) in PBS for $30 \mathrm{~min}$, followed by incubation with phalloidin-Alexa-488 (Invitrogen) in 1\% BSAPBS. Methoxy-X04 and phalloidin staining was simultaneously imaged using a Zeiss LSM 510 META LNO two-photon microscope.

Determination of $A \beta$ levels in interstitial fluid and plasma. In vivo microdialysis to assess brain interstitial fluid (ISF) $\mathrm{A} \beta_{1-\mathrm{x}}$ in the hippocampus of awake, freely moving Tg2576 mice was performed as previously described (Cirrito et al., 2003, 2005a). Ten to $12 \mathrm{~h}$ after microdialysis probe insertion, LY411,575 was administered subcutaneously at $3 \mathrm{mg} / \mathrm{kg}$ body weight in corn oil. ISF $\mathrm{A} \beta_{1-\mathrm{x}}$ was assessed using a sandwich ELISA; a central domain, mouse monoclonal antibody $(\mathrm{m} 266)$ was used to capture and a biotinylated $\mathrm{N}$-terminal, human $\mathrm{A} \beta$-specific antibody (m3D6) was used to detect, followed by streptavidin-poly-HRP-20 (Fitzgerald Industries). Plasma $\mathrm{A} \beta_{1-\mathrm{x}}$ levels were measured similarly, except the plasma was first denatured in $5 \mathrm{M}$ guanidine for $30 \mathrm{~min}$ at room temperature, then diluted to $500 \mathrm{~mm}$ final for use in the ELISA. The assay was developed using Slow ELISA TMB (Sigma) and read on a Bio-Tek FL-600 plate reader at $650 \mathrm{~nm}$.

Statistical analyses. Data were expressed as means \pm SEM. Comparison among multiple groups were performed with a one-way ANOVA followed by Dunnett's multiple comparison method. $P$ value $<0.05$ was considered significant.

\section{Results}

\section{CAA deposits increased with age in $\mathrm{Tg} 2576$ mice}

To assess progression of CAA deposits in the leptomeningial arteries, $A \beta$ that was deposited in a $\beta$-pleated sheet structure was visualized using a congo red derivative fluorescent dye, methoxyX04 (Fig. 1). Consistent with previous reports (Hsiao et al., 1996; Kawarabayashi et al., 2001; Fryer et al., 2003), we found no parenchymal or vascular amyloid deposits in 6-month-old Tg2576 mice (Fig. 1A). Substantial CAA deposits, however, were noted in 12-month-old Tg2576 mice (Fig. 1B,D). These deposits were typically patchy in nature with spacing between affected vessel segments. By 15 months of age, CAA deposits in Tg2576 mice had substantially progressed to encompass almost the entire leptomeningeal arteriolar system without interruption (Fig. 1C). 


\section{Vessel dysfunction in young Tg2576 mice lacking CAA}

Vasodilatory response to hypercapnia was decreased by $48 \%$ in young $\mathrm{Tg} 2576$ mice (pre-CAA) compared with age-matched, littermate wild type (WT) mice (Tg2576 mice: $14.5 \pm 2.5 \%$ vs WT mice: $27.7 \pm$ $5.1 \% ; p=0.0233$ ) (Fig. $2 B$ ). The attenuated vasodilatory response could not be attributed to differences between groups in extent of $\mathrm{pCO}_{2}$ change after induced hypercapnia (Table 1), other physiological parameters (Table 1), or baseline vascular diameters (Fig. 2C). A similar reduction in vessel response to topical ACh and SNAP was also noted in young $\mathrm{Tg} 2576$ mice compared with age-matched, littermate WT mice (ACh-Tg2576 mice: $11.4 \pm$ $2.2 \%$ vs WT mice: $20.5 \pm 2.6 \% ; p=0.009$; SNAP-Tg2576 mice: $20.0 \pm 3.7 \%$ vs WT mice: $33.9 \pm 2.6 \%$; $p=0.003$ ) (Fig. $2 D$ ). These data confirm that young $\mathrm{Tg} 2576$ mice have significant impairment in vascular reactivity and indicate that under our experimental conditions this is primarily the consequence of VSMC dysfunction.

\section{Further vessel dysfunction in older} Tg2576 mice having extensive CAA Hypercapnia-induced vasodilation was even further reduced by $85 \%$ in older Tg2576 mice having extensive CAA (Tg2576 mice: $4.1 \pm 2.0 \%$ vs WT mice: $25.3 \pm 3.0 \%$; $p<0.0001$ ) (Fig. $2 B$ ). To more specifically examine the relationship between CAA deposits and vessel function, we compared amyloid load across individual $25 \mu \mathrm{m}$ vessel segments (reported as \% CAA) to the vasodilatory function across the given vessel segment. In those segments having no or minimal CAA (i.e., $0-10 \%$ CAA), we noted significant reduction in hypercapnia-induced vasodilation compared with vessel segments from agematched, littermate WT mice (Fig. 3B). Cerebrovascular function was further compromised in vessel segments having $11-20 \%$ CAA, and vascular response was completely abolished in vessel segments have $>20 \%$ CAA (Fig. 3B). These alterations in vasodilatory response could not be attributed to extent of $\mathrm{pCO}_{2}$ change after induced hypercapnia or to other physiological parameters between groups (Table 1). These data strongly implicate CAA as a causal factor in the cerebrovascular dysfunction of older $\mathrm{Tg} 2576$ mice.

\section{Relationship between CAA and cerebral} vessel structural integrity

To explore whether alterations in VSMC architecture and/or density accounted for the observed cerebrovascular dysfunction, we sought to rigorously characterize vessel wall changes in
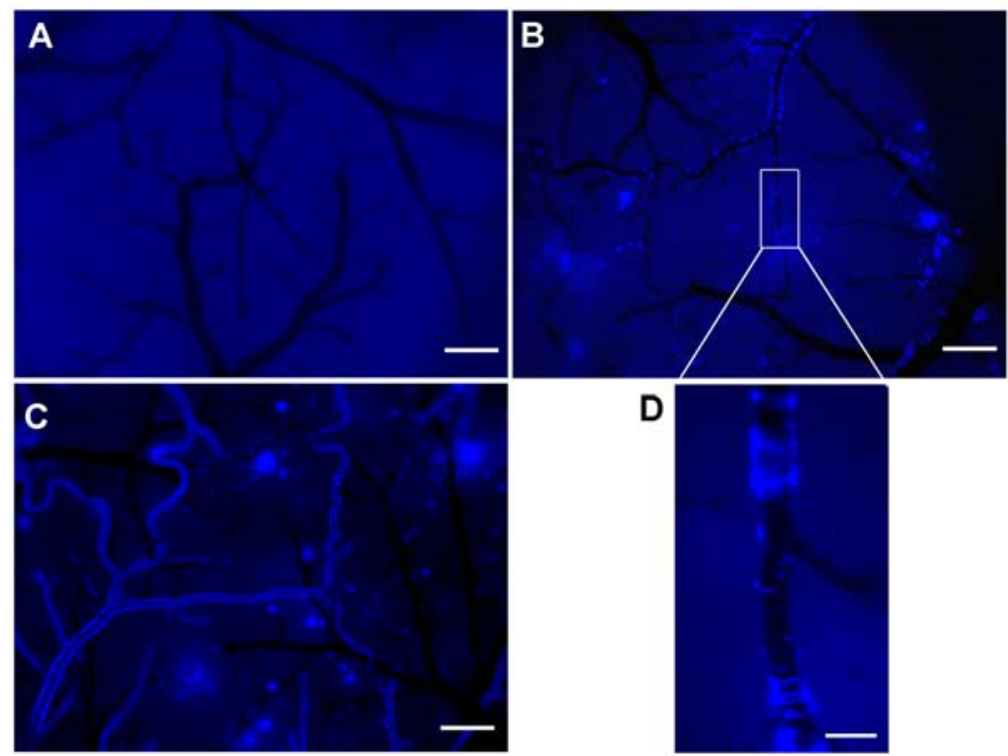

D

Figure 1. Progression of CAA in Tg2576 mice. Fluorescent microscopic images were taken $24 \mathrm{~h}$ after intraperitoneal injection of methoxy-X04 through a closed cranial window in 6- $(\boldsymbol{A}), 12-(\boldsymbol{B}, \boldsymbol{D})$, and 15- $(\boldsymbol{C})$ month-old Tg2576 mice. Neither CAA deposits nor parenchymal $A \beta$ plaques was noted in 6-month-old mice $(A)$. At 12 months of age, methoxy-X04-positive $A \beta$ deposition (bright blue) in the pial arterioles was prominent but patchy $(\boldsymbol{B}, \boldsymbol{D})$. By 15 months of age, CAA deposits were further progressed to almost the entire pial arteriole system without interruption (C). Scale bars: $A-C, 200 \mu \mathrm{m}, \boldsymbol{D}, 50 \mu \mathrm{m}$.
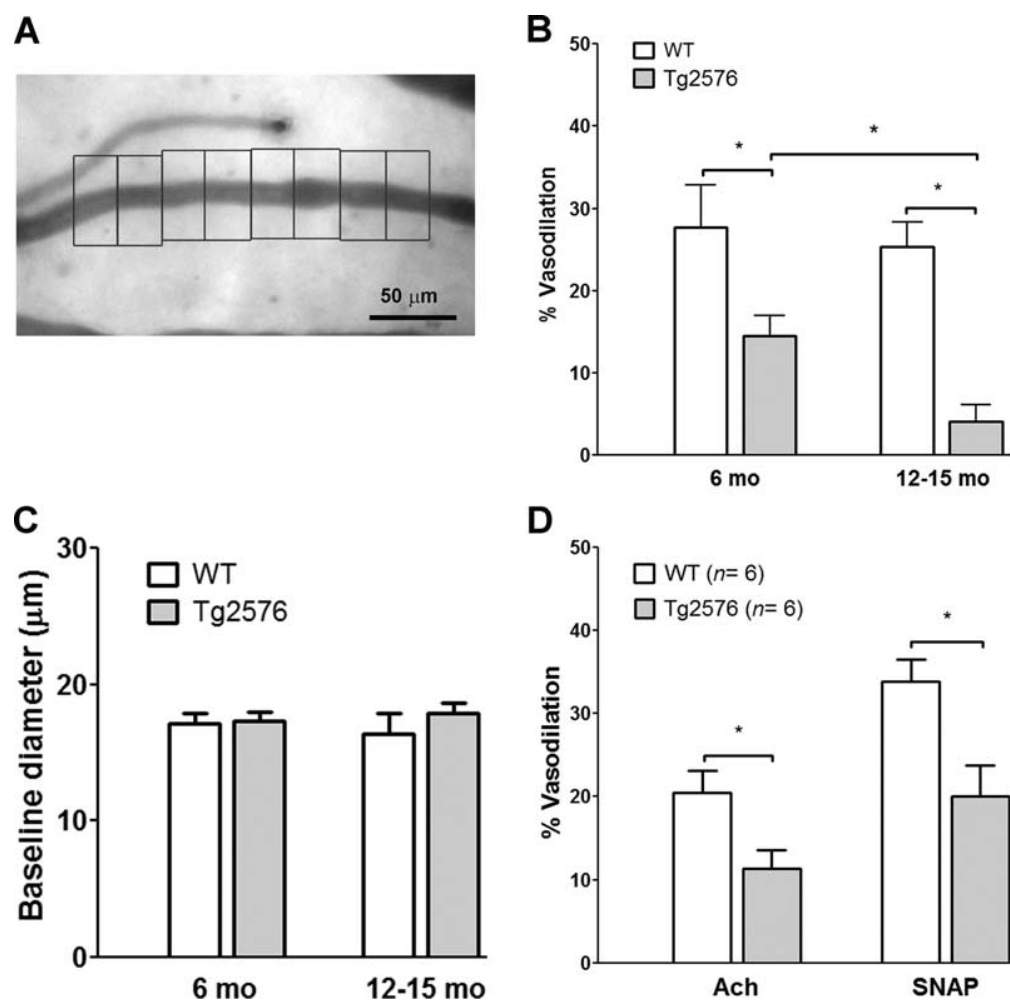

D

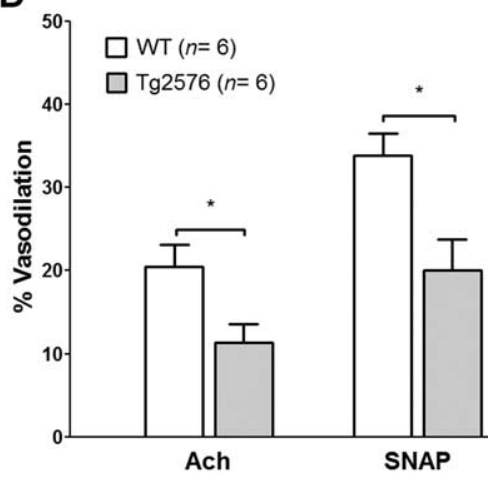

Figure 2. Cerebrovascular dysfunction in Tg2576 mice. Vascular responses to vasodilatory stimuli in the leptomeningeal arterioles through a closed cranial window were visualized and monitored via video microscopy in 6-month-old and 12- to 15-month-old Tg2576 mice. $A$, To determine vessel diameter, an average vessel diameter in $25-\mu \mathrm{m}$-long vessel segments (8 consecutive segments per animal) was measured using a Diamtrak software. $\boldsymbol{B}$, Vasodilatory response to hypercapnia. Percentage changes in vessel diameter were calculated and represented as mean \pm SEM. C, Baseline vessel diameters were similar between groups before exposure to hypercapnia. $\boldsymbol{D}$, Vascular responses to ACh and SNAP were attenuated in 6-month-old Tg2576 mice lacking CAA.

Tg2576 mice. In young mice, no CAA was found and VSMCs were arranged closely in parallel in all examined pial arterioles (Fig. $4 B, C a$ ). At 12 months of age, CAA deposits were found between VSMCs (Fig. $4 D-F$ ). In vessels having small amounts of 
Table 1. Physiological parameters pre-hypercapnia and post-hypercapnia

\begin{tabular}{|c|c|c|c|c|c|c|c|c|c|}
\hline \multirow[b]{2}{*}{ Group } & \multirow[b]{2}{*}{$n$} & \multicolumn{2}{|c|}{$\mathrm{pCO}_{2}(\mathrm{mmHg})$} & \multicolumn{2}{|l|}{$\mathrm{MBP}(\mathrm{mmHg})$} & \multicolumn{2}{|l|}{$\mathrm{pH}$} & \multicolumn{2}{|l|}{$\mathrm{pO}_{2}(\mathrm{mmHg})$} \\
\hline & & Pre & Post & Pre & Post & Pre & Post & Pre & Post \\
\hline 6 months, WT & 7 & $31.1 \pm 1.1$ & $56.1 \pm 2.4$ & $76.4 \pm 2.6$ & $75.1 \pm 2.9$ & $7.43 \pm 0.01$ & $7.23 \pm 0.01$ & $160.5 \pm 3.7$ & $157.7 \pm 2.7$ \\
\hline 6 months, $\mathrm{Tg}$ & 8 & $28.2 \pm 1.8$ & $51.1 \pm 4.8$ & $65.9 \pm 2.7$ & $69.6 \pm 4.5$ & $7.44 \pm 0.03$ & $7.28 \pm 0.03$ & $142.9 \pm 12.6$ & $165.0 \pm 3.6$ \\
\hline 12-15 months, WT & 8 & $31.5 \pm 1.1$ & $60.0 \pm 1.1$ & $65.9 \pm 3.1$ & $72.9 \pm 3.3$ & $7.46 \pm 0.03$ & $7.31 \pm 0.03$ & $158.5 \pm 2.7$ & $151.8 \pm 1.7$ \\
\hline 12-15 months, Tg & 8 & $32.4 \pm 0.8$ & $61.9 \pm 1.7$ & $79.3 \pm 8.3$ & $81.4 \pm 7.8$ & $7.51 \pm 0.05$ & $7.23 \pm 0.04$ & $158.0 \pm 6.3$ & $145.9 \pm 3.1$ \\
\hline
\end{tabular}

Mean arterial pressure (MAP) and blood gases were analyzed before (Pre) and 5 min after (Post) induction of hypercapnia. Data indicate mean \pm SEM.
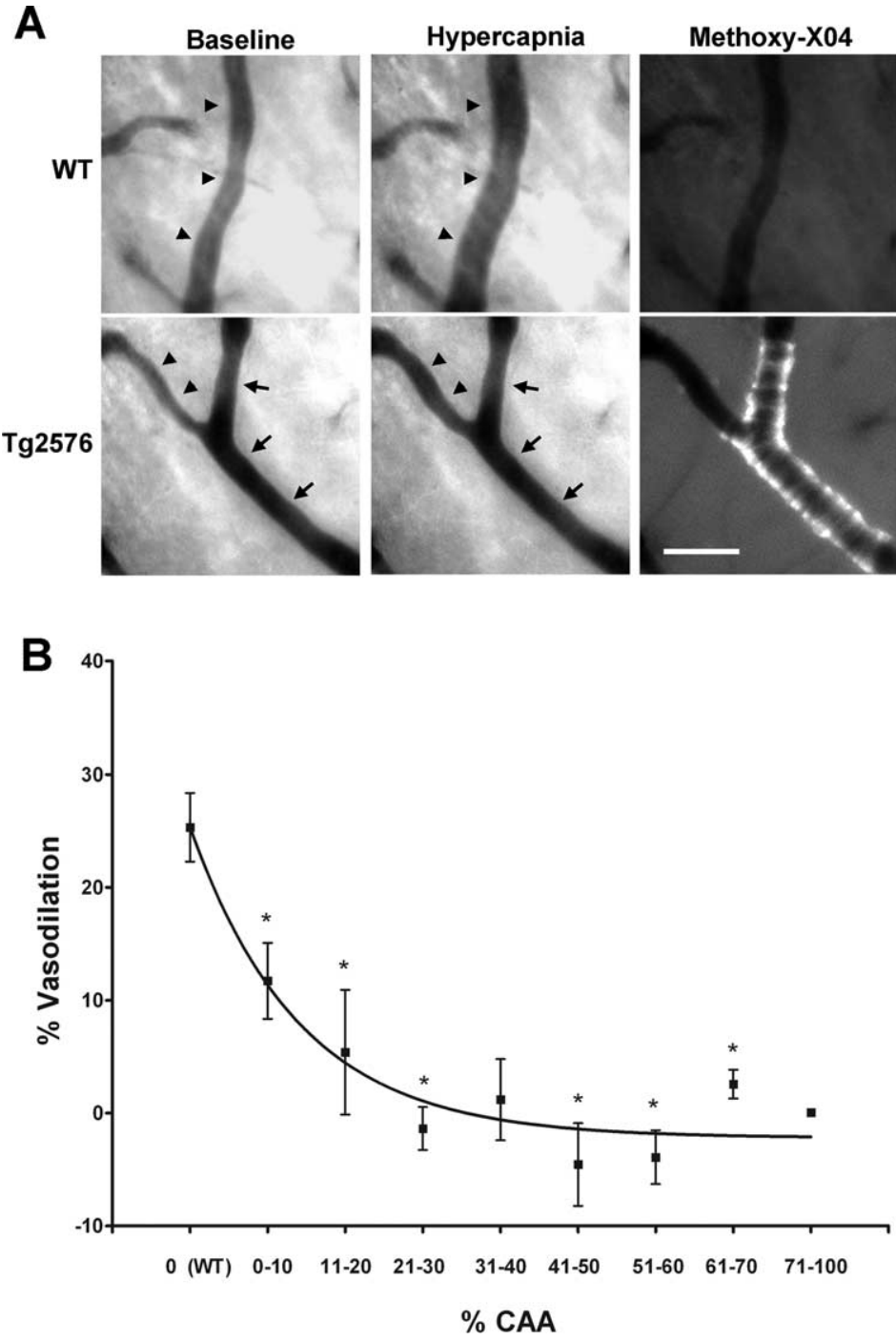

Figure 3. Vascular function was severely reduced in CAA-affected vessels. $A$, Live images of the leptomeningeal arterioles of 12- to 15-month-old WT and Tg2576 mouse brains were taken before (baseline) and 4 min after the onset of hypercapnia. Methoxy-X04-positive CAA deposits were imaged in the same vessels. In WT mice, vasodilatory response to hypercapnia was evident across the entire vessel segments (arrowheads). In Tg2576 mice, however, hypercapnia-induced vasodilation was noted in vessels without CAA (arrowheads), whereas there was little to no vascular response within the CAA-affected vessels (arrows). Scale bar, $100 \mu \mathrm{m} . \boldsymbol{B}$, Relationship between vasodilatory function and CAA coverage. Percentage CAA coverage within $25 \mu \mathrm{m}$ longitudinal vessels ( 8 consecutive segments per brain) were assessed as described in the Materials and Methods. CAA coverage was plotted against vasodilatory response to hypercapnia. Data indicate mean \pm SEM. ${ }^{*} p<0.05$ compared with WT mice analyzed by one-way ANOVA followed by Dunnett's test.

CAA $(<20 \%)$, no or minimal disruption of VSMC topography was noted and circumferential amyloid deposition was distinctly rare (Fig. $4 D-F b$ ). However, when greater amounts of CAA were present $(>20 \%)$, architectural VSMC changes became increasingly frequent and more severe, particularly when extent of CAA reached very high levels $(>40 \%)$ (Fig. $4 D-F c, d)$. At 15 months of age, VSMCs were extensively dismantled throughout the pial vessels, as CAA deposition had progressed to the point of nearcontinuous involvement of the arteriole system (Fig. 4G-Ie). These architectural changes were not apparent in age-matched WT mice (data not shown).

We also examined VSMC density. In WT mice of all examined ages, we found $\sim 20$ VSMCs per $100 \mu \mathrm{m}$ vessel segment (Fig. 5A). In young Tg2576 mice, VSMC density did not differ from age-matched WT mice. In older Tg2576 mice, however, decreased overall VSMC density was noted (Tg2576 mice: $15.5 \pm 0.5$ cells $/ 100 \mu \mathrm{m}$ vs WT mice: $20.6 \pm 1.3$ cells $/ 100 \mu \mathrm{m} ; p<$ $0.05)$. A correlative analysis between CAA load and VSMC density was performed, and a strong correlation between CAA severity (measured as \% CAA) and VSMC density was noted $\left(R^{2}=0.506 ; p<0.001\right)$ (Fig. $5 B$ ). Specifically, unaffected or mildly affected vessels (i.e., 0-20\% CAA) had no VSMC loss, moderately affected vessels (i.e., 21-40\% CAA) had a nonsignificant trend for VSMC loss, and severely affected vessels (i.e., $>40 \%$ CAA) had substantial and significant VSMC loss (Fig. 5C). Finally, a positive correlation between vessel caliber and severity of CAA deposits was noted $\left(R^{2}=0.3588, p<0.001\right)$ (Fig. $\left.5 D\right)$. These data suggest that mild amounts of CAA have no or minimal effect on vessel wall integrity, but as increasing amounts of CAA develop significant disruptions of vessel wall integrity including frank loss of VSMCs occur.

\section{$\gamma$-Secretase inhibition restores vascular} function in Tg2576 mice

Our results and those of others (Zhang et al., 1997; Iadecola et al., 1999; Niwa et al., 2000b, 2002a,b; Paris et al., 2004; Park et al., 2004, 2005, 2008) suggest that soluble $\mathrm{A} \beta$ can cause significant vessel dysfunction. However, decreasing endogenous $\mathrm{A} \beta$

levels or blocking its function followed by assessment of vasoreactivity has not been performed. We hypothesized that acute depletion of soluble $\mathrm{A} \beta$ via $\gamma$-secretase inhibition would improve vessel function. We assessed vessel reactivity in young Tg2576 mice in the presence and absence of significant extracellular brain and plasma human $\mathrm{A} \beta$ using the blood-brain barrier permeable $\gamma$-secretase inhibi- 


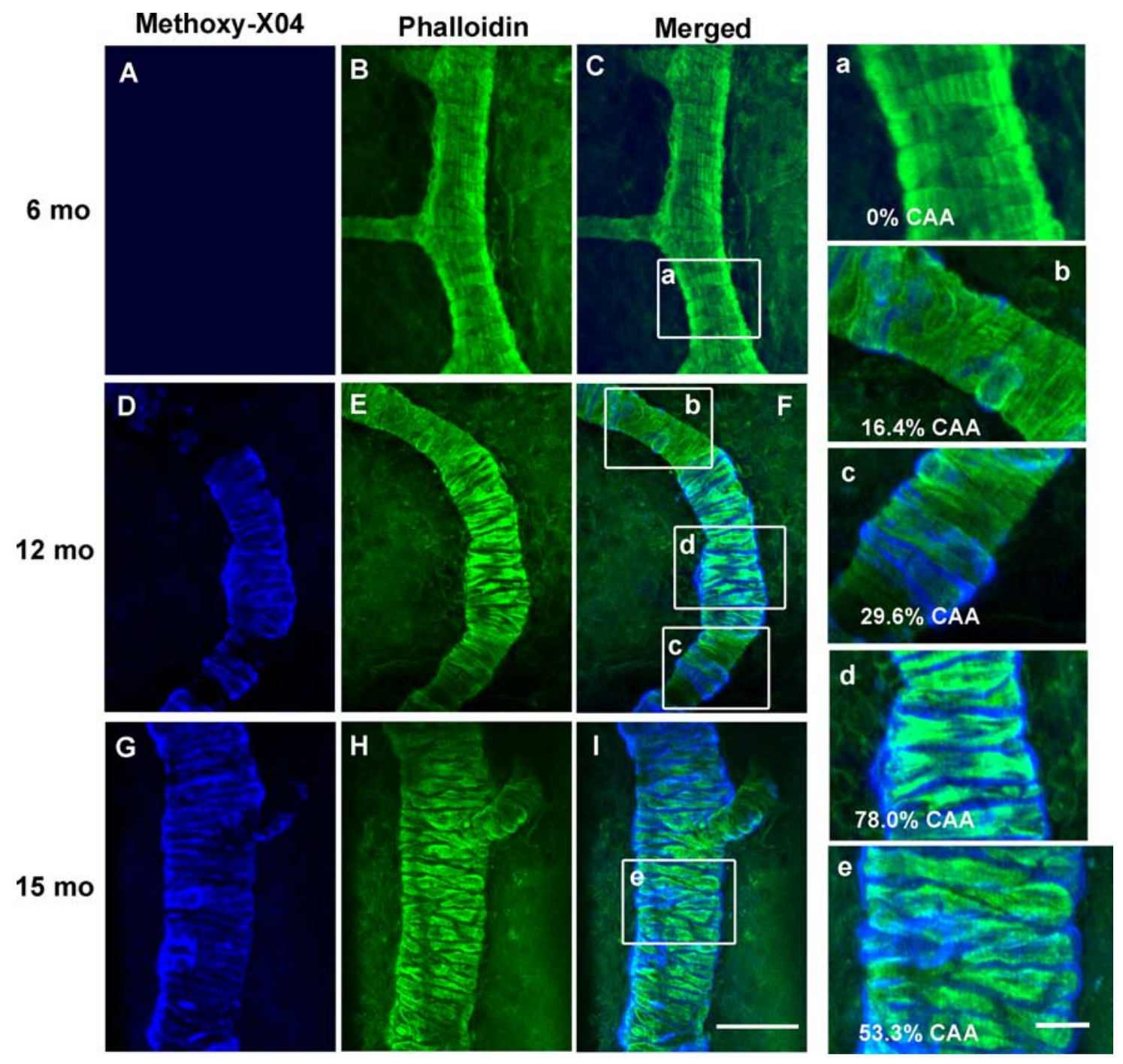

Figure 4. Disruption of vascular smooth muscle cells was noted in CAA-affected vessels. Amyloid deposition and vascular smooth muscle cells (VSMCs) in the leptomeningeal vessels were stained with methoxy-X04 (blue) and phalloidin-Alexa 488 (green), respectively, and imaged with a two-photon microscope. In 6-month-old Tg2576 mice having no CAA deposits, VSMCs were arranged closely in parallel to each other in the leptomeningeal vessels $(\boldsymbol{A}-\boldsymbol{C} \boldsymbol{a})$. At 12 months of age, the VSMC architecture had no or minimal disruption in the pial arterioles having small amounts of $C A A$ $(\boldsymbol{D}-\boldsymbol{F b}, \boldsymbol{C})$, whereas severe disruption of VSMC arrangement in the vessel segments had greater amounts of CAA ( $\boldsymbol{D}-\boldsymbol{F \boldsymbol { d }})$. Structural VSMC changes became more evident and severe in 15 -month-old mice (G-le). Scale bars: $A-I, 50 \mu \mathrm{m}, \boldsymbol{a}-\boldsymbol{e}, 20 \mu \mathrm{m}$.

tor, LY411,575 (Cirrito et al., 2003; Best et al., 2005). Similar to previous results (Cirrito et al., 2005b), subcutaneous administration of LY411,575 (3 mg/kg) in young Tg2576 mice resulted in almost complete depletion of soluble human $\mathrm{A} \beta_{1-\mathrm{x}}$ pool in the interstitial fluid (ISF) up to $36 \mathrm{~h}$ after drug administration (Fig. $6 A)$. It also markedly reduced the soluble human $\mathrm{A} \beta_{1-\mathrm{x}}$ pool in plasma (vehicle-treated group: $17.2 \pm 2.1 \mathrm{ng} / \mathrm{ml}$ vs LY511,475treated group: $3.3 \pm 0.9 \mathrm{ng} / \mathrm{ml}, p<0.05$ ) (data not shown). Although LY411,575 did not affect baseline vessel diameters in leptomeningeal arteries (Fig. $6 \mathrm{~B}$ ), it did substantially restore cerebral vasodilatory responses in young $\mathrm{Tg} 2576$ mice (but not WT mice) (Fig. 6C,D). Vessel function was not improved after administration of the inactive form of the $\gamma$-secretase inhibitor, LY424,196 (Fig. 6C). These data implicate soluble human A $\beta$ as a causative agent in cerebrovascular impairment of young Tg 2576 mice. The effect of murine $A \beta$ on cerebrovascular function, however, appeared negligible, as LY411,575 treatment in WT mice decreased murine $\mathrm{A} \beta$ in ISF (data not shown) but did not alter cerebrovascular function (Fig. 6C).

We next examined whether $\gamma$-secretase inhibition was capable of restoring vasomotor function in 12-month-old Tg2576 mice having extensive CAA. We found that LY411,575 treatment produced a small but significant improvement in cerebral arteriole function compared with vehicle-treated animals (Fig. 6F). Importantly, this partial restoration of vasodilatory response to hypercapnia resulted entirely from functional improvement in vessels having small amounts of CAA (i.e., $\leq 20 \%$ CAA), whereas no effect was noted in more severely affected vessels (i.e., $>20 \%$ CAA) (Fig. 6G). Of note, acute LY411,575 treatment had no appreciable effect on CAA severity within vessel walls (Fig. $6 E$ ), strongly suggesting that reduction in soluble human $\mathrm{A} \beta$ was responsible for the improved vessel function.

\section{Discussion}

Our principal findings are as follows: (1) soluble and insoluble forms of $\mathrm{A} \beta$ contribute to age-dependent cerebrovascular dysfunction in Tg2576 mice; (2) CAA-induced cerebrovascular impairment develops via dysfunction rather than frank loss or disruption of VSMCs; and (3) acute depletion of soluble $\mathrm{A} \beta$ via 

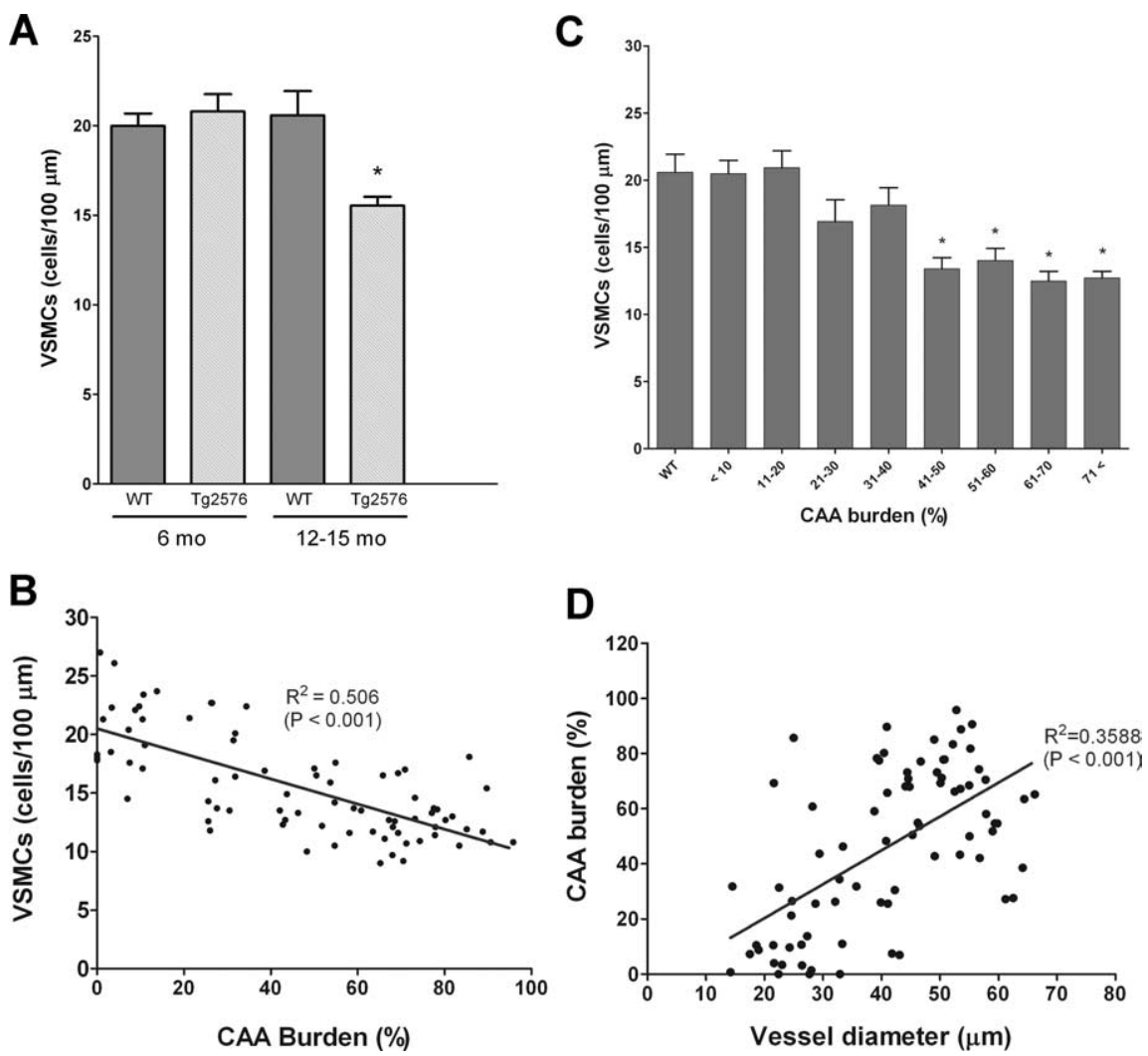

Figure 5. Correlation between CAA coverage and VSMC loss. A number of VSMCs and CAA coverage were assessed as described in the Materials and Methods. $\boldsymbol{A}$, A number of VSMCs were decreased in the leptomeningeal vessels of 12-to 15 -month-old, but not 6-month-old Tg2576 mice compared with age-matched WT mice $(p<0.05)$. $\boldsymbol{B}$, At $12-15$ months of age, VSMC loss was markedly noted in the leptomeningeal vessel segments having $>40 \%$ CAA coverage. $C$, Correlation between CAA severity and VSMC loss. $D$, Correlation between vessel caliber versus severity of CAA deposits in the leptomeningeal vessels $\left(R^{2}=0.3588, p<\right.$ 0.001).

$\gamma$-secretase inhibition significantly restores vessel function in young and to a lesser degree older Tg2576 mice.

\section{Vascular dysfunction in young $\mathrm{Tg} 2576$ mice}

Our results indicate that soluble A $\beta$ induces significant cerebrovascular dysfunction. First, we demonstrated that young Tg2576 mice having elevated soluble A $\beta$ levels (but no CAA) had markedly reduced cerebrovascular responses to vasodilatory stimuli. This is consistent with the majority of previous reports (Iadecola et al., 1999; Niwa et al., 2000a,b; Niwa et al., 2002a,b; Park et al., 2004, 2005, 2008; Tong et al., 2005). Second, we found that vessel dysfunction in young Tg2576 mice was substantially restored after acute depletion of soluble $A \beta$ via administration of the $\gamma$-secretase inhibitor, LY411,575. The latter finding is enlightening for two reasons. (1) It provides further support to the notion that disrupted cerebrovascular regulation in young $\mathrm{Tg} 2576$ mice is due to soluble $\mathrm{A} \beta$ and not APP overexpression [although further confirmatory experiments are required because $\gamma$-secretase is known to cleave not only APP but also other type-I membrane proteins (Wolfe, 2007)]. (2) It demonstrates that cerebrovascular dysfunction in young APP mice is reversible within hours of A $\beta$ depletion, an important finding not only in regards to mechanism but also in the context of potential $\mathrm{A} \beta$-directed therapeutics for cerebrovascular disease.

\section{Vascular dysfunction in older Tg2576 mice}

Results from our study also implicate insoluble vascular $\mathrm{A} \beta$ (i.e., CAA) in causing significant and often severe cerebrovascular dys- function. We documented a differential impairment in vasomotor function in young (pre-CAA) vs older (extensive CAA) Tg2576 mice, with the former having 50\% impairment and the latter having $85 \%$ impairment in hypercapnia-induced vasodilation. This result, along with that of other investigators who have also documented marked cerebrovascular dysfunction in older Tg2576 mice (Christie et al., 2001; Shin et al., 2007; Park et al., 2008), strongly but indirectly linked CAA to vessel dysfunction. It remained possible that worsened vessel function in older $\operatorname{Tg} 2576$ mice might result from prolonged exposure to increased levels of soluble $\mathrm{A} \beta$ and/or APP rather than a direct consequence of vascular amyloid. To more directly implicate CAA, we next examined how CAA severity across a given vessel segment affects its vasodilatory response. By comparing vascular reactivity across variously affected CAA vessels in same age mice in which length and extent of exposure to soluble $\mathrm{A} \beta$ (at least globally) and APP were constant, these two potential confounds were effectively controlled. With this method, we identified a significant dose-response between extent of CAA and degree of impaired vasomotor function, a result that more definitively implicates CAA as a causal factor accounting for the severity of vasomotor dysfunction noted in older Tg2576 mice.

One surprising finding from this analysis was that relatively small amounts of CAA were associated with either substantial vessel dysfunction (11-20\% CAA) or complete vasomotor paralysis (>20\% CAA). Although previous studies (Christie et al., 2001; Shin et al., 2007; Park et al., 2008) have shown substantial cerebrovascular impairment in CAAaffected Tg2576 mice, the extent of CAA necessary to affect vessel function remained unknown. Our results show that extensive CAA is not required to produce marked vessel dysfunction, suggesting that simple mechanical or architectural changes (e.g., circumferential amyloid deposition that could mechanically restrict vessel reactivity, or amyloid-induced loss or disruption of VSMCs that might preclude a coordinated vasodilatory response) do not fully account for CAA-associated vasomotor dysfunction. Results from our assessment of CAA's effect on vessel wall integrity support this contention. For example, although CAA severity correlated well with VSMC loss, a threshold effect was identified whereby a certain quantity of CAA must be reached before significant VSMC loss occurs. In our experiments this threshold was $>40 \%$ CAA. Yet significant CAA-related vessel dysfunction began at 11-20\% CAA and complete vessel shutdown occurred at $>20 \%$ CAA. Moreover, at these levels of CAA, minimal VSMC disruption and rare circumferential amyloid deposition were present. In total, these results indicate that mechanisms such as simple mechanical or architectural effects of CAA are not responsible for the observed vasomotor paralysis. Rather, certain molecular effectors are likely present and represent the true mediators of CAA's deleterious effect on cerebrovascular function. These data also suggest that therapies targeting 



Figure 6. Blockade of $A \beta$ production restored vascular function in Tg2576 mice. $A$, The blood-brain barrier permeable $\gamma$-secretase inhibitor, LY 411,575 depleted soluble $A \beta_{1-x}$ levels in the interstitial fluid (ISF) in 6-month-old Tg2576 mice. LY411,575 (3 mg/kg) was subcutaneously administered and human A $\beta 1$-x levels in the ISF were assayed as described in the Materials and Methods. Data represent mean \pm SEM $(n=5) . \boldsymbol{B}$, Baseline vessel diameters were analyzed in the leptomeningeal arterioles before and $3 \mathrm{~h}$ after LY411,575 treatment in 6-month-old Tg2576 and WT mice. C, D, Six-month-old WT or Tg2576 mice treated with vehicle (Veh), LY411,575 (LY), or the inactive form LY424,196 (inactive LY) were subjected to vascular function tests in response to hypercapnia $(\boldsymbol{C}), A C h(100 \mu \mathrm{M})(\boldsymbol{D})$, or SNAP $(500 \mu \mathrm{M})(\boldsymbol{D})(n=7-9)$. $\boldsymbol{E}$, In 12- to 15-month-old Tg2576 mice, CAA deposits were fluorescently labeled with methoxy-X04 and photographically imaged before (green) and $15 \mathrm{~h}$ after (red) the LY411,575 treatment. Scale bar, $20 \mu \mathrm{m}$. F, G, Vascular reactivity was examined in 12- to 15-month-old Tg2576 mice $15 \mathrm{~h}$ after treatment with vehicle or LY411,575 $(n=5)$. Vascular reactivity was analyzed in all vessel segments $(\boldsymbol{F})$ and further compared in vessels having $\leq 20 \%$ versus $>20 \%$ CAA coverage (G). Note that LY411,575 restored vascular function in cerebral arterioles with little or no CAA ( $\leq 20 \%$ coverage), but had no effect in vessels with extensive CAA ( $>20 \%$ coverage). ${ }^{*} p<0.05$ as analyzed by ANOVA followed by Dunnett's multiple comparison test.

CAA or its downstream molecular effectors may need to be instituted at relatively early stages of the disease process, because more advanced CAA and its attendant VSMC changes (especially frank cell loss) may represent a "point of no return" beyond which therapeutic strategies may prove futile.

Finally, we examined whether $\gamma$-secretase inhibition could restore function in CAA-ladened vessels. Administration of the $\gamma$-secretase inhibitor, LY411,575, led to a small but significant improvement in the vasodilatory capacity of older Tg2576 mice. This improvement, however, was only seen in vessels with small amounts of CAA $(<20 \%)$, whereas no effect was noted in more advanced stages of CAA $(>20 \%)$. Because acute administration of LY411,575 depleted A $\beta$ pools, did not affect CAA severity, and substantially restored vessel function in young $\mathrm{Tg} 2576$ having no CAA, the parsimonious explanation for the improved vessel function in older Tg2576 mice is its interruption of soluble A $\beta$ 's effect on cerebral vessels. It is important to note that the magnitude of improved vessel function was substantially less in older vs young Tg2576 mice. One explanation is that the coexisting presence of small amounts of CAA prevented full restoration of the vasodilatory response to hypercapnia. Another explanation is that the local presence of CAA, which is likely in dynamic equilibrium with soluble forms of $A \beta$, prevented full depletion of soluble $\mathrm{A} \beta$ in the perivascular space. Regardless of specific mechanism, the demonstration of improved vasomotor function after $\mathrm{A} \beta$-directed therapy in CAA-affected vessels is an important finding, because it demonstrates at least some capacity for restoration of cerebrovascular function in the face of coexisting vas- cular amyloid, a finding that could have significant clinical implications for both $\mathrm{AD}$ and CAA.

\section{Mechanisms of $A \boldsymbol{\beta}$-induced vasomotor impairment}

Our results suggest that both soluble and insoluble forms of $\mathrm{A} \beta$ cause vasomotor impairment at least in part via VSMC dysfunction. For example, we noted impaired vascular responses to hypercapnia and SNAP in young Tg2576 mice, both of which suggest abnormal VSMC function. Although some studies have noted similar results using VSMC-dependent vasodilators such as SNAP (Park et al., 2005) and calcitonin gene-related peptide (Tong et al., 2005), others have found conflicting results using hypercapnia (Iadecola et al., 1999; Park et al., 2008) and VSMCdependent vasodilators such as sodium nitroprusside (Tong et al., 2005) and adenosine (Park et al., 2005, 2008). These discrepancies may result from differences in specific experimental methodology, including variations in anesthetic, method of cerebrovascular assessment, preferred vasoactive stimuli, and/or line of APP transgenic mice. More experiments will be needed to clarify this important issue.

Our study noted even greater impairment of hypercapniainduced vasodilation in CAA-ladened vessels of older Tg2576 mice. When coupled with the findings of Christie et al. (2001) who demonstrated impaired vascular reactivity to sodium nitroprusside (a VSMC-dependent vasodilator) in older Tg2576 mice, these results suggest that VSMC dysfunction is likely to be a key pathophysiologic event underlying CAA-induced vasomotor impairment. Given the known pathological effects of fibrillar amy- 
loid on VSMCs (Van Nostrand et al., 1998, 2001; Muñoz et al., 2002) and the nature and severity of VSMC dysfunction noted in older Tg2576 mice (this study; Christie et al., 2001), it is logical and attractive to hypothesize that VSMC dysfunction is an essential underlying cellular event responsible for CAA-induced cerebrovascular dysfunction.

In regards to the underlying molecular pathways leading to $\mathrm{A} \beta$-induced cerebrovascular dysfunction, much is known for soluble A $\beta$. Both reactive oxygen species (ROS) (Iadecola, 2004; Hamel et al., 2008) and proinflammatory pathways (Paris et al., 2003 ) have been causally linked to soluble $A \beta$-induced vasoactivity and the cerebrovascular dysfunction of young APP mice. In particular NADPH oxidase-derived oxygen radicals appear to play a central role, as Park and colleagues demonstrated that genetic inactivation of the Nox2 catalytic subunit of NADPH oxidase led to near complete restoration of the cerebrovascular abnormalities in young Tg2576 mice (Park et al., 2005). However, investigations into the molecular underpinnings of CAAinduced vessel dysfunction have only just begun. To date, three mechanistic studies examining cerebrovascular dysfunction in older APP mice have been reported (Tong et al., 2005; Nicolakakis et al., 2008; Park et al., 2008), but only one used mice having substantial amounts of CAA (Park et al., 2008). In that study, Park and colleagues again used a genetic approach to investigate the role of NADPH oxidase, but in this case they examined older Tg2576 mice having substantial vascular as well as parenchymal amyloid (Park et al., 2008). They found that older Tg2576 mice lacking the Nox2 catalytic subunit of NADPH oxidase did not develop significant vasomotor impairment, suggesting a potential role for ROS in CAA-induced vessel dysfunction. However, it is important to note that the method of cerebrovascular assessment used in this study (i.e., regional cerebral blood flow via laser doppler flowmetry) did not permit direct functional evaluation of CAA-ladened vessels. Therefore, additional experiments to confirm the role of ROS and NADPH oxidase in CAAinduced vasomotor impairment are required.

\section{Conclusion}

Our work supports the findings of previous investigators who documented age-dependent impairment of cerebrovascular function in APP transgenic mice. In addition, our observations extend on these studies on several fronts. One, we demonstrated for the first time that both young and older Tg2576 mice can display significant cerebrovascular dysfunction under uniform experimental conditions. Two, we more directly implicated CAA as a causal factor in cerebrovascular dysfunction by demonstrating a dose-response to CAA severity and by controlling for confounds such as prolonged exposure to soluble $A \beta$ and mutant APP. Three, we provided robust evidence that CAA-related vessel dysfunction begins before significant alterations in vessel wall integrity, indicating that downstream molecular effectors likely exist and are the true mediators of CAA-induced cerebrovascular dysfunction. Four, we identified VSMC dysfunction as a likely key cellular event underlying CAA-induced cerebrovascular impairment. And five, we provided evidence supporting the concept that $\mathrm{A} \beta$-directed therapy may prove a viable strategy toward attenuating $\mathrm{A} \beta$-induced cerebrovascular dysfunction. Whether restoration of vasoreactivity via $\gamma$-secretase inhibition or other $\mathrm{A} \beta$-directed therapy ultimately parlays into improved cerebral blood flow, reduced ischemic brain injury, and/or enhanced cognitive function will be an important future issue to be assessed.

\section{References}

Best JD, Jay MT, Otu F, Ma J, Nadin A, Ellis S, Lewis HD, Pattison C, Reilly M, Harrison T, Shearman MS, Williamson TL, Atack JR (2005) Quantitative measurement of changes in amyloid- $\beta(40)$ in the rat brain and cerebrospinal fluid following treatment with the $\gamma$-secretase inhibitor LY411,575 [N2-[(2S)-2-(3,5-difluorophenyl)-2-hydroxyethanoyl]-N1[(7S)-5-methyl-6-oxo-6,7-dihydro-5H-dibenzo[b,d]azepin-7-yl]-Lalaninamide]. J Pharmacol Exp Ther 313:902-908.

Brendza RP, Bacskai BJ, Cirrito JR, Simmons KA, Skoch JM, Klunk WE, Mathis CA, Bales KR, Paul SM, Hyman BT, Holtzman DM (2005) AntiAbeta antibody treatment promotes the rapid recovery of amyloidassociated neuritic dystrophy in PDAPP transgenic mice. J Clin Invest 115:428-433.

Breteler MM (2000) Vascular risk factors for Alzheimer's disease: an epidemiologic perspective. Neurobiol Aging 21:153-160.

Cadavid D, Mena H, Koeller K, Frommelt RA (2000) Cerebral beta amyloid angiopathy is a risk factor for cerebral ischemic infarction. A case control study in human brain biopsies. J Neuropathol Exp Neurol 59:768-773.

Christie R, Yamada M, Moskowitz M, Hyman B (2001) Structural and functional disruption of vascular smooth muscle cells in a transgenic mouse model of amyloid angiopathy. Am J Pathol 158:1065-1071.

Cirrito JR, May PC, O'Dell MA, Taylor JW, Parsadanian M, Cramer JW, Audia JE, Nissen JS, Bales KR, Paul SM, DeMattos RB, Holtzman DM (2003) In vivo assessment of brain interstitial fluid with microdialysis reveals plaque-associated changes in amyloid-beta metabolism and halflife. J Neurosci 23:8844-8853.

Cirrito JR, Yamada KA, Finn MB, Sloviter RS, Bales KR, May PC, Schoepp DD, Paul SM, Mennerick S, Holtzman DM (2005a) Synaptic activity regulates interstitial fluid amyloid-beta levels in vivo. Neuron 48:913-922.

Cirrito JR, Deane R, Fagan AM, Spinner ML, Parsadanian M, Finn MB, Jiang H, Prior JL, Sagare A, Bales KR, Paul SM, Zlokovic BV, Piwnica-Worms D, Holtzman DM (2005b) P-glycoprotein deficiency at the blood-brain barrier increases amyloid-beta deposition in an Alzheimer disease mouse model. J Clin Invest 115:3285-3290.

de la Torre JC (2004) Is Alzheimer's disease a neurodegenerative or a vascular disorder? Data, dogma, and dialectics. Lancet Neurol 3:184-190.

Esiri MM, Nagy Z, Smith MZ, Barnetson L, Smith AD (1999) Cerebrovascular disease and threshold for dementia in the early stages of Alzheimer's disease. Lancet 354:919-920.

Fryer JD, Taylor JW, DeMattos RB, Bales KR, Paul SM, Parsadanian M, Holtzman DM (2003) Apolipoprotein E markedly facilitates agedependent cerebral amyloid angiopathy and spontaneous hemorrhage in amyloid precursor protein transgenic mice. J Neurosci 23:7889-7896.

Glenner GG, Henry JH, Fujihara S (1981) Congophilic angiopathy in the pathogenesis of Alzheimer's degeneration. Ann Pathol 1:120-129.

Golde TE (2005) The Abeta hypothesis: leading us to rationally-designed therapeutic strategies for the treatment or prevention of Alzheimer disease. Brain Pathol 15:84-87.

Golde TE, Eckman CB, Younkin SG (2000) Biochemical detection of Abeta isoforms: implications for pathogenesis, diagnosis, and treatment of Alzheimer's disease. Biochim Biophys Acta 1502:172-187.

Greenberg SM, Vonsattel JP, Stakes JW, Gruber M, Finklestein SP (1993) The clinical spectrum of cerebral amyloid angiopathy: presentations without lobar hemorrhage. Neurology 43:2073-2079.

Hamel E, Nicolakakis N, Aboulkassim T, Ongali B, Tong XK (2008) Oxidative stress and cerebrovascular dysfunction in mouse models of Alzheimer's disease. Exp Physiol 93:116-120.

Hock C, Villringer K, Müller-Spahn F, Wenzel R, Heekeren H, Schuh-Hofer S, Hofmann M, Minoshima S, Schwaiger M, Dirnagl U, Villringer A (1997) Decrease in parietal cerebral hemoglobin oxygenation during performance of a verbal fluency task in patients with Alzheimer's disease monitored by means of near-infrared spectroscopy (NIRS)-correlation with simultaneous rCBF-PET measurements. Brain Res 755:293-303.

Holtzman DM, Fagan AM, Mackey B, Tenkova T, Sartorius L, Paul SM, Bales K, Ashe KH, Irizarry MC, Hyman BT (2000) Apolipoprotein E facilitates neuritic and cerebrovascular plaque formation in an Alzheimer's disease model. Ann Neurol 47:739-747.

Hsiao K, Chapman P, Nilsen S, Eckman C, Harigaya Y, Younkin S, Yang F, Cole G (1996) Correlative memory deficits, Abeta elevation, and amyloid plaques in transgenic mice. Science 274:99-102. 
Iadecola C (2004) Neurovascular regulation in the normal brain and in Alzheimer's disease. Nat Rev Neurosci 5:347-360.

Iadecola C, Zhang F, Niwa K, Eckman C, Turner SK, Fischer E, Younkin S, Borchelt DR, Hsiao KK, Carlson GA (1999) SOD1 rescues cerebral endothelial dysfunction in mice overexpressing amyloid precursor protein. Nat Neurosci 2:157-161.

Itoh Y, Yamada M, Hayakawa M, Otomo E, Miyatake T (1993) Cerebral amyloid angiopathy: a significant cause of cerebellar as well as lobar cerebral hemorrhage in the elderly. J Neurol Sci 116:135-141.

Jagust WJ, Haan MN, Reed BR, Eberling JL (1998) Brain perfusion imaging predicts survival in Alzheimer's disease. Neurology 51:1009-1013.

Jellinger KA (2002) The pathology of ischemic-vascular dementia: an update. J Neurol Sci 203-204:153-157.

Kawarabayashi T, Younkin LH, Saido TC, Shoji M, Ashe KH, Younkin SG (2001) Age-dependent changes in brain, CSF, and plasma amyloid (beta) protein in the Tg2576 transgenic mouse model of Alzheimer's disease. J Neurosci 21:372-381.

Klunk WE, Bacskai BJ, Mathis CA, Kajdasz ST, McLellan ME, Frosch MP, Debnath ML, Holt DP, Wang Y, Hyman BT (2002) Imaging Abeta plaques in living transgenic mice with multiphoton microscopy and methoxy-X04, a systemically administered Congo red derivative. J Neuropathol Exp Neurol 61:797-805.

Lim A, Tsuang D, Kukull W, Nochlin D, Leverenz J, McCormick W, Bowen J, Teri L, Thompson J, Peskind ER, Raskind M, Larson EB (1999) Cliniconeuropathological correlation of Alzheimer's disease in a communitybased case series. J Am Geriatr Soc 47:564-569.

Mandybur TI (1975) The incidence of cerebral amyloid angiopathy in Alzheimer's disease. Neurology 25:120-126.

Mann DM, Iwatsubo T, Ihara Y, Cairns NJ, Lantos PL, Bogdanovic N, Lannfelt L, Winblad B, Maat-Schieman ML, Rossor MN (1996) Predominant deposition of amyloid-beta 42(43) in plaques in cases of Alzheimer's disease and hereditary cerebral hemorrhage associated with mutations in the amyloid precursor protein gene. Am J Pathol 148:1257-1266.

Mentis MJ, Alexander GE, Krasuski J, Pietrini P, Furey ML, Schapiro MB, Rapoport SI (1998) Increasing required neural response to expose abnormal brain function in mild versus moderate or severe Alzheimer's disease: PET study using parametric visual stimulation. Am J Psychiatry 155:785-794.

Muñoz FJ, Opazo C, Gil-Gómez G, Tapia G, Fernández V, Valverde MA, Inestrosa NC (2002) Vitamin E but not 17beta-estradiol protects against vascular toxicity induced by beta-amyloid wild type and the Dutch amyloid variant. J Neurosci 22:3081-3089.

Nicolakakis N, Aboulkassim T, Ongali B, Lecrux C, Fernandes P, Rosa-Neto P, Tong XK, Hamel E (2008) Complete rescue of cerebrovascular function in aged Alzheimer's disease transgenic mice by antioxidants and pioglitazone, a peroxisome proliferator-activated receptor gamma agonist. J Neurosci 28:9287-9296.

Niwa K, Carlson GA, Iadecola C (2000a) Exogenous A beta1-40 reproduces cerebrovascular alterations resulting from amyloid precursor protein overexpression in mice. J Cereb Blood Flow Metab 20:1659-1668.

Niwa K, Younkin L, Ebeling C, Turner SK, Westaway D, Younkin S, Ashe KH, Carlson GA, Iadecola C (2000b) Abeta 1-40-related reduction in functional hyperemia in mouse neocortex during somatosensory activation. Proc Natl Acad Sci U S A 97:9735-9740.

Niwa K, Kazama K, Younkin SG, Carlson GA, Iadecola C (2002a) Alterations in cerebral blood flow and glucose utilization in mice overexpressing the amyloid precursor protein. Neurobiol Dis 9:61-68.

Niwa K, Kazama K, Younkin L, Younkin SG, Carlson GA, Iadecola C (2002b) Cerebrovascular autoregulation is profoundly impaired in mice overexpressing amyloid precursor protein. Am J Physiol Heart Circ Physiol 283:H315-H323.
Okazaki H, Reagan TJ, Campbell RJ (1979) Clinicopathologic studies of primary cerebral amyloid angiopathy. Mayo Clin Proc 54:22-31.

Paris D, Humphrey J, Quadros A, Patel N, Crescentini R, Crawford F, Mullan M (2003) Vasoactive effects of A beta in isolated human cerebrovessels and in a transgenic mouse model of Alzheimer's disease: role of inflammation. Neurol Res 25:642-651.

Paris D, Quadros A, Humphrey J, Patel N, Crescentini R, Crawford F, Mullan M (2004) Nilvadipine antagonizes both Abeta vasoactivity in isolated arteries, and the reduced cerebral blood flow in APPsw transgenic mice. Brain Res 999:53-61.

Park L, Anrather J, Forster C, Kazama K, Carlson GA, Iadecola C (2004) Abeta-induced vascular oxidative stress and attenuation of functional hyperemia in mouse somatosensory cortex. J Cereb Blood Flow Metab 24:334-342.

Park L, Anrather J, Zhou P, Frys K, Pitstick R, Younkin S, Carlson GA, Iadecola C (2005) NADPH-oxidase-derived reactive oxygen species mediate the cerebrovascular dysfunction induced by the amyloid beta peptide. J Neurosci 25:1769-1777.

Park L, Zhou P, Pitstick R, Capone C, Anrather J, Norris EH, Younkin L, Younkin S, Carlson G, McEwen BS, Iadecola C (2008) Nox2-derived radicals contribute to neurovascular and behavioral dysfunction in mice overexpressing the amyloid precursor protein. Proc Natl Acad Sci U S A 105:1347-1352

Premkumar DR, Cohen DL, Hedera P, Friedland RP, Kalaria RN (1996) Apolipoprotein E-epsilon4 alleles in cerebral amyloid angiopathy and cerebrovascular pathology associated with Alzheimer's disease. Am J Pathol 148:2083-2095.

Prohovnik I, Mayeux R, Sackeim HA, Smith G, Stern Y, Alderson PO (1988) Cerebral perfusion as a diagnostic marker of early Alzheimer's disease. Neurology 38:931-937.

Selkoe DJ (2001) Alzheimer's disease: genes, proteins, and therapy. Physiol Rev 81:741-766.

Shin HK, Jones PB, Garcia-Alloza M, Borrelli L, Greenberg SM, Bacskai BJ, Frosch MP, Hyman BT, Moskowitz MA, Ayata C (2007) Age-dependent cerebrovascular dysfunction in a transgenic mouse model of cerebral amyloid angiopathy. Brain 130:2310-2319.

Sisodia SS (1999) Alzheimer's disease: perspectives for the new millennium. J Clin Invest 104:1169-1170.

Snowdon DA, Greiner LH, Mortimer JA, Riley KP, Greiner PA, Markesbery WR (1997) Brain infarction and the clinical expression of Alzheimer disease. The Nun Study. Jama 277:813-817.

Tong XK, Nicolakakis N, Kocharyan A, Hamel E (2005) Vascular remodeling versus amyloid beta-induced oxidative stress in the cerebrovascular dysfunctions associated with Alzheimer's disease. J Neurosci 25:11165-11174.

Van Nostrand WE, Melchor JP, Ruffini L (1998) Pathologic amyloid betaprotein cell surface fibril assembly on cultured human cerebrovascular smooth muscle cells. J Neurochem 70:216-223.

Van Nostrand WE, Melchor JP, Cho HS, Greenberg SM, Rebeck GW (2001) Pathogenic effects of D23N Iowa mutant amyloid beta-protein. J Biol Chem 276:32860-32866.

Vermeer SE, Prins ND, den Heijer T, Hofman A, Koudstaal PJ, Breteler MM (2003) Silent brain infarcts and the risk of dementia and cognitive decline. N Engl J Med 348:1215-1222.

Vinters HV (1987) Cerebral amyloid angiopathy. A critical review. Stroke 18:311-324.

Wolfe MS (2007) gamma-Secretase modulators. Curr Alzheimer Res 4:571-573.

Zhang F, Eckman C, Younkin S, Hsiao KK, Iadecola C (1997) Increased susceptibility to ischemic brain damage in transgenic mice overexpressing the amyloid precursor protein. J Neurosci 17:7655-7661. 